\title{
Effect of different activating agents on the production of activated carbon from Raw Date Fronds of Saudi Palm Trees
}

\author{
Ashfaq Ahmad, Hassan Mohammed Al-Swaidan, Ahmad Hamed Al-Ghamdi
}

\begin{abstract}
In this study activated carbon (AC) was prepared from raw date's fronds (RDFs) of Saudi palm trees through a single step chemical activation method using $\mathrm{H}_{3} \mathrm{PO}_{4}, \mathrm{KOH}$ and $\mathrm{ZnCl}_{2}$. The effects of different parameters such as, concentrations, carbonization temperature and carbonization time (dwell time), on the BET surface area of ACs were studied. The raw date's frond charcoal (RDFC) and ACs were characterized by Thermogravimetric analysis (TGA), nitrogen adsorption BrunauerEmmett-Teller (BET) surface area and Scanning Electron Microscopy (SEM). The highest BET surface area $1901 \mathrm{~m}^{2} \mathrm{~g}^{-1}, 1581$ $\mathrm{m}^{2} \mathrm{~g}^{-1}$ and $607 \mathrm{~m}^{2} \mathrm{~g}^{-1}$ were obtained at optimum condition of $60 \%$ $\mathrm{H}_{3} \mathrm{PO}_{4}, \mathrm{ZnCl}_{2}$ and $40 \% \mathrm{KOH}$ concentration respectively at $400^{\circ} \mathrm{C}$ carbonization temperature for $3 \mathrm{~h}$ carbonization time.
\end{abstract}

Keywords-Activated carbon, Date Fronds, Chemical Activation, Surface area.

\section{Introduction}

The properties of ACs are largely depended on the methods of activation and types of precursor materials. Lignocellulosic biomass wastes are very important cheap and renewable materials precursor of ACs. This Agricultural Biomass wastes are significant precursor material for the preparation of ACs. AC synthesized from biomass has high surface area, porosity and high carbon yield. AC is porous, solid and black carbon containing materials $[1,2]$. ACs is an outstanding adsorbent due to high porosity, large surface area, surface reactivity, large adsorption capacity and ease of regeneration [3].

ACs is used extensively in different fields like air and gas pollution control, pharmaceutical, food and chemical industries, for the decolorization of vegetable oil, wastewater purification, catalyst support, toxic heavy metals removal from drinking water and recovery of solvents, $[4,5]$.

Lignocellulosic wastes are low-cost and renewable materials precursor for ACs production. ACs were prepared from

Ashfaq Ahmad

College of Science / King Saud University Riyadh

Kingdom of Saudi Arabia

Professor Hassan M. Al-Swaidan

College of Science/ King Saud University Riyadh

Kingdom of Saudi Arabia

Professor Ahmad Hamed Alghamdi

College of Science/ King Saud University Riyadh Kingdom of Saudi Arabia numerous sources of biomass waste materials including coconut shell and husk, palm oil shells, cotton stalks, durian shell, rice husk, jackfruit peel and pomegranate seeds [6-13] etc.

ACs preparation methods are classified as physical and chemical activation. Physical method is two steps, first the carbonization of the precursor materials at high temperature in inert atmosphere followed by activation with oxidizing gases such as steam, carbon dioxide and oxygen etc. Chemical activation is a single step method, in which the carbonization of the precursor materials is carried out at low temperature in the presence of a chemical activating agent [14-16].

The most extensively used chemical activating agents for ACs preparation are phosphoric acid, zinc Chloride, potassium hydroxide, sulfuric acid and hydrochloric acid [17-21].

The most abundant cultivating plant in Saudi Arabia is the date palm. It is one of the cash crops in Saudi Arabia. The date palm trees in the kingdom are more than 20 million. During cutting process about 15 frond branches from each palm tree in per year prune by the cultivator. The weight of each frond branch is about one $\mathrm{Kg}$. These estimates show that in Saudi Arabia about 300000 tons of date fronds are produced per year $[22,23]$.

In continuation to our previous work, in the present research work the preparation of ACs from biomass (RDF) waste was carried out by chemical activation with $\mathrm{H}_{3} \mathrm{PO}_{4}, \mathrm{KOH}$ and $\mathrm{ZnCl}_{2}$. The effect of different concentration, carbonization temperature and carbonization time (dwell time) on the BET surface areas, morphology and chemical changes of the ACs were evaluated.

\section{Experimental}

\section{A. Materials}

The RDF samples were collected from Agriculture Research date plants garden in King Saud University Riyadh (KSA). The date's fronds were cut it into small pieces and dried in the sun. The RDFs were washed after completely dried in the sun with water to remove all the impurities. The RDFs were dried in Oven (Gallenkamp size one BS) for $5 \mathrm{~h}$ at $105^{\circ} \mathrm{C}$. Finally the completely dried RDFs were crushed using grinder into powder and sieved by $0.160 \mathrm{~mm}$ mesh (Retsch 4188 type prufsieb/Sieve). The chemicals used for activation and washing in this study are $\mathrm{ZnCl}_{2} 97 \%$ (BDH England), hydrochloric acid $37 \%$ (Riedel-de Haen USA), $\mathrm{H}_{3} \mathrm{PO}_{4} 85 \%$ (MERCK Germany), $\mathrm{NaOH} 97.5 \%$ (BDH England) and $\mathrm{KOH}$ 85-100\% (BDH England). 


\section{B. Preparation of activated carbon}

$\mathrm{AC}$ was prepared by first impregnation of powder RDF in activating agents followed by carbonization. Different concentrations of activating agent solutions were prepared in range of 20 to $100 \%$ with the increment of $20 \%$ by dissolving all activating agents in distilled water.

Powder RDF were socked in all activating agent's solutions separately at room temperature and allowed for $24 \mathrm{~h}$. The samples were filtered to remove the excess activating agent's solution and dried in oven at $100^{\circ} \mathrm{C}$ for $4 \mathrm{~h}\left(\mathrm{H}_{3} \mathrm{PO}_{4}\right), 6 \mathrm{~h}$ at $120^{\circ} \mathrm{C}\left(\mathrm{ZnCl}_{2}\right)$ and at $100^{\circ} \mathrm{C}$ for $3 \mathrm{~h}(\mathrm{KOH})$. The dried samples were carbonized at different temperature and dwell time in muffle furnace (XY-1200 XinYu). After carbonization, the ACs were cooled at room temperature and then washed with 0.5 mol. $\mathrm{L}-1 \mathrm{HCl}$ solutions for $\mathrm{ZnC}_{12}, \mathrm{KOH}$ and $0.5 \mathrm{~mol}$. $\mathrm{L}^{-1}$ $\mathrm{NaOH}$ solutions for $\mathrm{H}_{3} \mathrm{PO}_{4}$ activated carbon. All the samples were washed with distilled water to remove the remaining chemicals until the effluent $\mathrm{PH}$ reached 6.8-7. The washed AC samples were dried in an oven at $110^{\circ} \mathrm{C}$. The ACs were prepared from RDF by chemical activation with different concentration of $\mathrm{H}_{3} \mathrm{PO}_{4}, \mathrm{KOH}$ and $\mathrm{ZnCl}_{2}$ such as 20 to $100 \%$ separately, different carbonization temperature $250-550^{\circ} \mathrm{C}$ with different carbonization time 1 to $5 \mathrm{~h}$ with $5^{\circ} \mathrm{C} / \mathrm{min}$ and $20^{\circ} \mathrm{C} / \mathrm{min}$ ramp rate respectively.

\section{Analysis and Characterization}

BET surface areas of ACs were determined by using Micromeritics (Gemini VII, 2390 USA) analyser through adsorption of nitrogen $\left(\mathrm{N}_{2}\right)$ at $77 \mathrm{~K}$. The samples were degassed at $150^{\circ} \mathrm{C}$ under nitrogen flow for $1 \mathrm{~h}$ to eliminate moisture and gasses before analysis. Thermogravimetric analysis (TA/TGA Q50) of RDF was carried out with heating rate $20^{\circ} \mathrm{C} / \mathrm{min}$ under $\mathrm{N}_{2}$ at $25-1000^{\circ} \mathrm{C}$ temperature, to find the suitable carbonization temperature for ACs preparation. The surface morphology of RDF and ACs at different activating agents were analyzed by scanning electron microscope (SEM) by using JEOL (JSM-6380 LA).

\section{Result and Discussion}

\section{A. Proximate analysis and chemical composition of RDF}

The method [24] was used for the proximate analysis, to determine the ash, moisture, fixed carbon and volatile matter content in the RDF are given in Table 1. Before proximate analysis, the precursor was dried in air at room temperature for a week. To calculate the moisture content, $1 \mathrm{~g}$ air dried RDF was placed in an oven at $110^{\circ} \mathrm{C}$ for $3 \mathrm{~h}$ until completely dehydration was occurred. To measure the volatile matter contents, dried sample of $1 \mathrm{~g}$ was placed for $7 \mathrm{~min}$ at $850^{\circ} \mathrm{C}$ in muffle furnace. The sample was cooled same as above and weighed to get the volatile amount in RDF. $1 \mathrm{~g}$ of precursor material was placed at $750^{\circ} \mathrm{C}$ for $3 \mathrm{~h}$ in muffle furnace, to determine the ash contents in RDF. Then crucible was cooled in desiccator and weighed the crucible to measure the ash contents in RDF. To determine the fixed carbon amount,
TABle.1 Properties of RDF DATE Palm Tree

\begin{tabular}{|l|l|l|l|l|l|l|}
\hline \multicolumn{3}{|c|}{ Proximate Analysis (Mass \%) } & \multicolumn{3}{c|}{ Chemical Composition (\%) } \\
\hline Volatile & Moisture & Ash & $\begin{array}{l}\text { Fixed } \\
\text { carbon }\end{array}$ & Cellulose & Hemicellulose & Lignin \\
\hline 74.6 & 9.1 & 6.0 & 10.3 & 44.0 & 29.8 & 26.2 \\
\hline
\end{tabular}

subtract the values calculated for moisture, volatile matter, and ash from $100 \%$. The RDF Chemical composition was carried out [25] and the \% of cellulose, hemicellulose and lignin were shown in Table 1.

\section{B. Thermogravimetric (TGA) analysis}

TGA was used to measure the amount of weight loss of sample with respect to temperature. Fig. 1 shows the thermogram of RDF in inert atmosphere of $\mathrm{N}_{2}$. The first stage of weight loss start from temperature 25 to $189.67^{\circ} \mathrm{C}$, which correspond to the loss of water and some light volatile compounds. The $\%$ weight loss at this temperature range is about $4.38 \%$. The second stage start from temperature 210 $347^{\circ} \mathrm{C}$ and about $54.40 \%$ weight loss occurred. The decomposition of lignocellulosic structure usually above $200^{\circ} \mathrm{C}$ begins [26]. This high amount of weight loss occurred because of rapid transfer of hemicelluloses, cellulose than lignin to gases and tars. The formation of carbon also begins in this step [27, 28]. Most of the lignin decomposes in 3rd step that occurs above $350^{\circ} \mathrm{C}$ up to $1000^{\circ} \mathrm{C}$ because it is slowly decompose than other two. The weight loss in the 3rd step gradually decreased. Thermogravimetric analysis TGA shows that carbonization of RDF occurred at around $400^{\circ} \mathrm{C}$.

\section{Effect of Concentration of Activating Agents on BET Surface Area}

The BET surface area of ACs produced at different concentration of $\mathrm{H}_{3} \mathrm{PO}_{4}, \mathrm{KOH}$ and $\mathrm{ZnCl}_{2}$ measured by $\mathrm{N}_{2}$

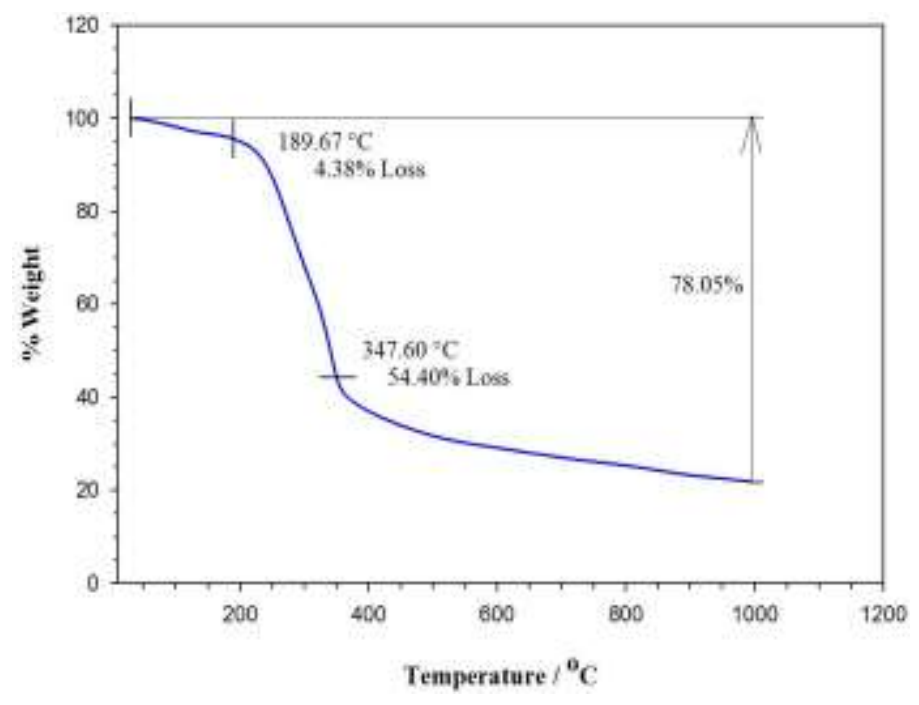

Fiigure 1. TGA diagram of RDF in a nitrogen atmosphere 
Proc. of the Third Intl. Conf. Advances in Bio-Informatics, Bio-Technology and Environmental Engineering- ABBE 2015 Copyright (C) Institute of Research Engineers and Doctors, USA .All rights reserved.

ISBN: 978-1-63248-060-6 doi: 10.15224/ 978-1-63248-060-6-05

adsorption are given in Table 2. The BET surface area of ACs increased with increase in concentration until $40 \%$ for $\mathrm{KOH}$ and $60 \%$ for $\mathrm{H}_{3} \mathrm{O}_{4}$ and $\mathrm{ZnCl}_{2}$. Further increase in concentrations the BET surface area (Fig. 2) (Table 2) of ACs are decreased. This shows that until $40 \%$ and $60 \%$ a well porous structure is formed, which is, however, destroyed when the concentration was increased to $100 \%$. The maximum BET surface areas obtained for AC60, $\mathrm{AC} 40$ at $60 \% \mathrm{H}_{3} \mathrm{PO}_{4}, \mathrm{ZnCl}_{2}$ and $40 \% \mathrm{KOH}$ are $1901 \mathrm{~m}^{2} \mathrm{~g}^{-1}, 1581 \mathrm{~m}^{2} \mathrm{~g}^{-1}$ and $607 \mathrm{~m}^{2} \mathrm{~g}^{-1}$ respectively.

\section{Effect of Carbonization Temperature on BET Surface Area}

The effect of different carbonization temperature from 250 to $550^{\circ} \mathrm{C}$ on the BET surface area of AC prepared from $\mathrm{H}_{3} \mathrm{PO}_{4}$, $\mathrm{KOH}$ and $\mathrm{ZnCl}_{2}$ are discussed in Table 3. The Raise of carbonization temperature increases the evaporation of volatile components and carbon burn off. The effects of carbonization temperature on the BET Surface area of the synthesized ACs

TABle. 2 EFFect of CONCENTRATION OF $\mathrm{H}_{3} \mathrm{PO}_{4}$, KOH AND $\mathrm{ZnCl}_{2}$ ON BET SURFACE AREA

\begin{tabular}{|l|c|c|c|}
\hline \multicolumn{1}{|c|}{ Label } & $\begin{array}{c}\mathbf{H}_{3} \mathbf{O P}_{\mathbf{4}} \text { BET } \\
\text { Surface Area } \\
\left(\mathbf{m}^{2} \mathbf{g}^{-\mathbf{1}}\right)\end{array}$ & $\begin{array}{c}\text { KOH BET Surface } \\
\text { Area } \\
\left(\mathbf{m}^{\mathbf{2}} \mathbf{g}^{-\mathbf{1}}\right)\end{array}$ & $\begin{array}{c}\mathbf{Z n C l}_{2} \text { BET } \\
\text { Surface Area } \\
\left(\mathbf{m}^{\mathbf{2}} \mathbf{g}^{-\mathbf{}}\right)\end{array}$ \\
\hline $\mathrm{AC}^{\mathrm{a}} 20 \%{ }^{\mathrm{b}}$ & 563 & 312 & 572 \\
\hline $\mathrm{AC} 40 \%$ & 977 & 607 & 1494 \\
\hline $\mathrm{AC} 60 \%$ & 1901 & 503 & 1581 \\
\hline $\mathrm{AC} 80 \%$ & 975 & 138 & 753 \\
\hline $\mathrm{AC} 100 \%$ & 905 & 107 & 857 \\
\hline
\end{tabular}

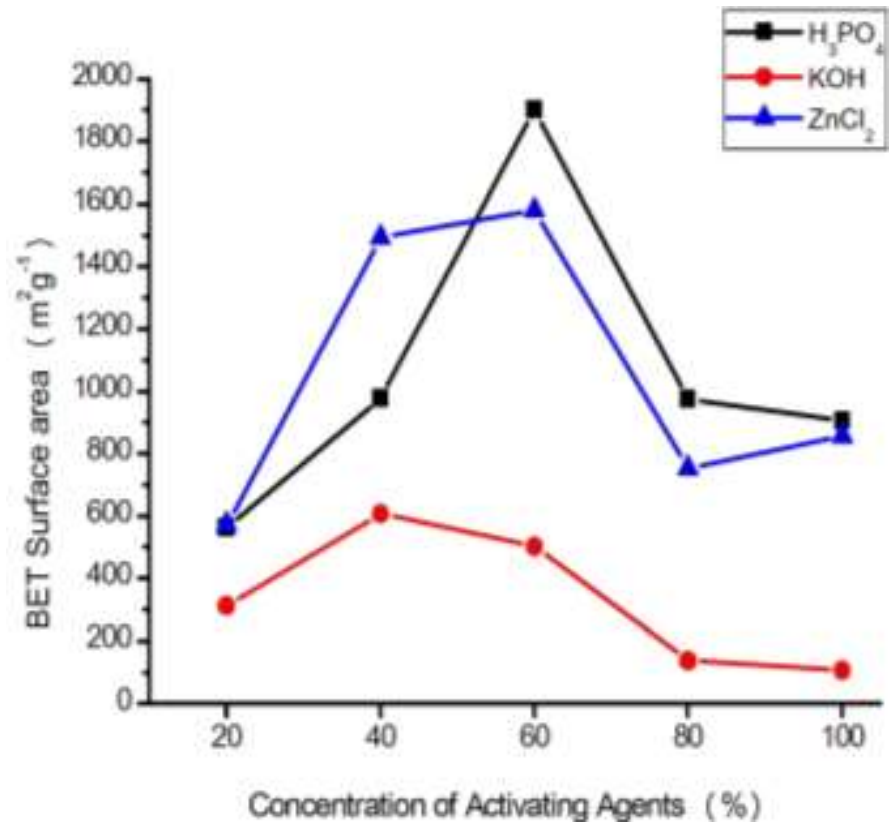

Figure 2. Effect of Concentration of $\mathrm{H}_{3} \mathrm{PO}_{4}, \mathrm{KOH}$ and $\mathrm{ZnCl}_{2}$ on BET Surface Area
TABle. 3 EFFect of Carbonization Temperature on BET Surface AREA

\begin{tabular}{|l|c|c|c|}
\hline \multicolumn{1}{|c|}{ Label } & $\begin{array}{c}\mathbf{H}_{\mathbf{3}} \mathbf{O P}_{\mathbf{4}} \text { BET } \\
\text { Surface Area } \\
\left(\mathbf{m}^{\mathbf{2}} \mathbf{- 1}\right)\end{array}$ & $\begin{array}{c}\text { KOH BET } \\
\text { Surface Area } \\
\left(\mathbf{m}^{\mathbf{2}} \mathbf{- 1}\right)\end{array}$ & $\begin{array}{c}\mathbf{Z n C l}_{\mathbf{2}} \text { BET } \\
\text { Surface Area } \\
\left(\mathbf{m}^{\mathbf{2}} \mathbf{g}^{-\mathbf{1}}\right)\end{array}$ \\
\hline $\mathrm{AC} 250^{\mathrm{b}}$ & 1085 & 343 & 886 \\
\hline $\mathrm{AC} 350$ & 1243 & 520 & 1167 \\
\hline $\mathrm{AC} 400$ & 1901 & 607 & 1581 \\
\hline $\mathrm{AC} 450$ & 1510 & 587 & 1535 \\
\hline $\mathrm{AC} 550$ & 1287 & 497 & 1303 \\
\hline
\end{tabular}

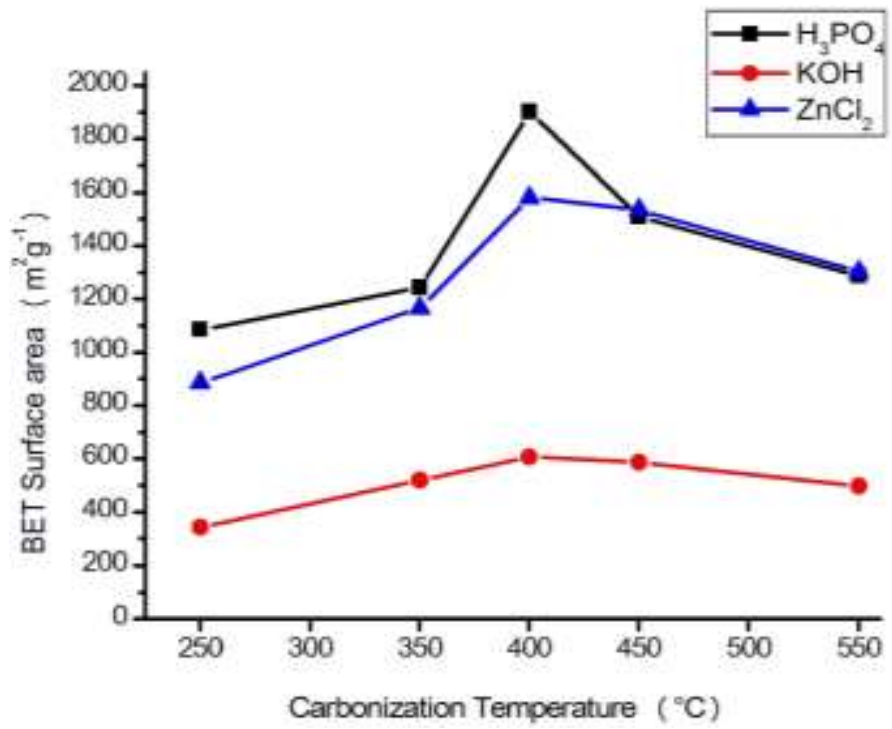

Fiigure 3. Effect of Carbonization Temperature on BET Surface Area

are stated in Fig. 3. Increasing the carbonization temperature from 250 to $400^{\circ} \mathrm{C}$ increase the present pores along with the new pores generation. The BET Surface area increasing with increase of carbonization temperature from 250 to $400^{\circ} \mathrm{C}$ and 400 to $550^{\circ} \mathrm{C}$ a decreasing trend of BET Surface area was observed. This decreasing trend of BET Surface area may be due rupture of pore (pore fusion) and accumulation of carbon in pores.

\section{E. Effect of Carbonization Time on BET Surface Area}

The effect of carbonization time 1-5 h on BET Surface area of ACs prepared from various activating agents were examined. The other activation parameters were remains constant, like ramp rate $5^{\circ} \mathrm{C}$ for $\mathrm{H}_{3} \mathrm{PO}_{4}, 20^{\circ} \mathrm{C}$ for $\mathrm{KOH}, \mathrm{ZnCl}_{2}$ and carbonization temperature $400^{\circ} \mathrm{C}$ for all activating agents. Table 4 shows the results of BET surface area of ACs prepared by various activating agents. The BET surface area increasing with carbonization time till $3 \mathrm{~h}$ and then decreasing up to $5 \mathrm{~h}$. High BET surface area was obtained at $3 \mathrm{~h}$ carbonization time as shown in Fig. 4. The carbonization time increasing from 1-3 $\mathrm{h}$ which effects the production of new pores and increase BET surface area, whereas above the $3 \mathrm{~h}$ carbonization temperature or (longer heating duration) pore 
Proc. of the Third Intl. Conf. Advances in Bio-Informatics, Bio-Technology and Environmental Engineering- ABBE 2015 Copyright (C) Institute of Research Engineers and Doctors, USA .All rights reserved.

ISBN: 978-1-63248-060-6 doi: 10.15224/ 978-1-63248-060-6-05

widening and collapse of some the pores occurs which decrease the BET surface area.

\section{F. Scanning Electron Microscopy (SEM)}

Figure 5 show the digital images of RDF (a) AC (b) and Scanning electron microscope (SEM) micrographs of RDFC (c), $\mathrm{AC}-\mathrm{H}_{3} \mathrm{PO}_{4}$ (d) $\mathrm{AC}-\mathrm{ZnCl}_{2}$ (e) and $\mathrm{AC}-\mathrm{KOH}$ (f) at optimum conditions. There are significant changes among the surface morphology of RDFC and ACs. The micrograph of RDFC shows that surface is in the form of curvy or wavy because of the presence of cellulose, hemicellulose and lignin (Fig. 5 c).

There are no pores and no slit like cracks available on the surface of RDFC and look like common lignocellulosic materials. However several large pores and cracks are developed on the surface of $\mathrm{AC}-\mathrm{H}_{3} \mathrm{PO}_{4}$ due to release of volatile organic and inorganic compounds by chemical activation (Fig. 5 d). The surface of AC-KOH (Fig. 5 e) shows some cracks and small amount of pores. The $\mathrm{AC}-\mathrm{ZnCl}_{2}$ micrograph (Fig. $5 \mathrm{f}$ ) shows numerous pores and cracks on surface. The high BET surface area produced with $\mathrm{AC}-\mathrm{H}_{3} \mathrm{PO}_{4}$ and $\mathrm{AC}-\mathrm{ZnCl}_{2}$ compared to $\mathrm{AC}-\mathrm{KOH}$ and $\mathrm{RDFC}$ is attributed to the presence of numerous pores and cracks.

TABLE.4. EFFECT OF CARBonization Time On BET SURFACE AREA

\begin{tabular}{|c|c|c|c|}
\hline Label & $\begin{array}{c}\mathrm{H}_{3} \mathrm{OP}_{4} \text { BET } \\
\text { Surface Area } \\
\left(\mathrm{m}^{2} \mathrm{~g}^{-1}\right) \\
\end{array}$ & $\begin{array}{c}\text { KOH BET } \\
\text { Surface Area } \\
\left(\mathrm{m}^{2} \mathrm{~g}^{-1}\right) \\
\end{array}$ & $\begin{array}{c}\mathbf{Z n C l}_{2} \text { BET Surface } \\
\text { Area } \\
\left(\mathbf{m}^{2} \mathbf{g}^{-1}\right) \\
\end{array}$ \\
\hline $\mathrm{AC}^{\mathrm{a}} 1^{\mathrm{b}}$ & 1653 & 443 & 1290 \\
\hline $\mathrm{AC} 2$ & 1730 & 503 & 1363 \\
\hline AC 3 & 1901 & 607 & 1581 \\
\hline AC 4 & 1218 & 545 & 1392 \\
\hline AC 5 & 1106 & 477 & 1308 \\
\hline
\end{tabular}

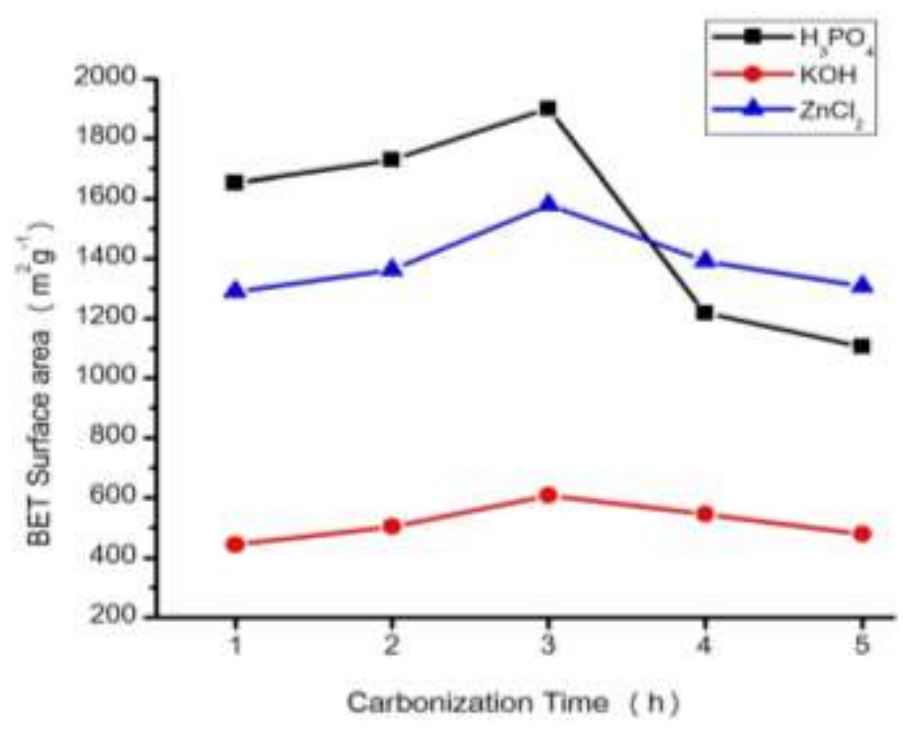

Figure 4. Effect of Carbonization Time on BET Surface Area
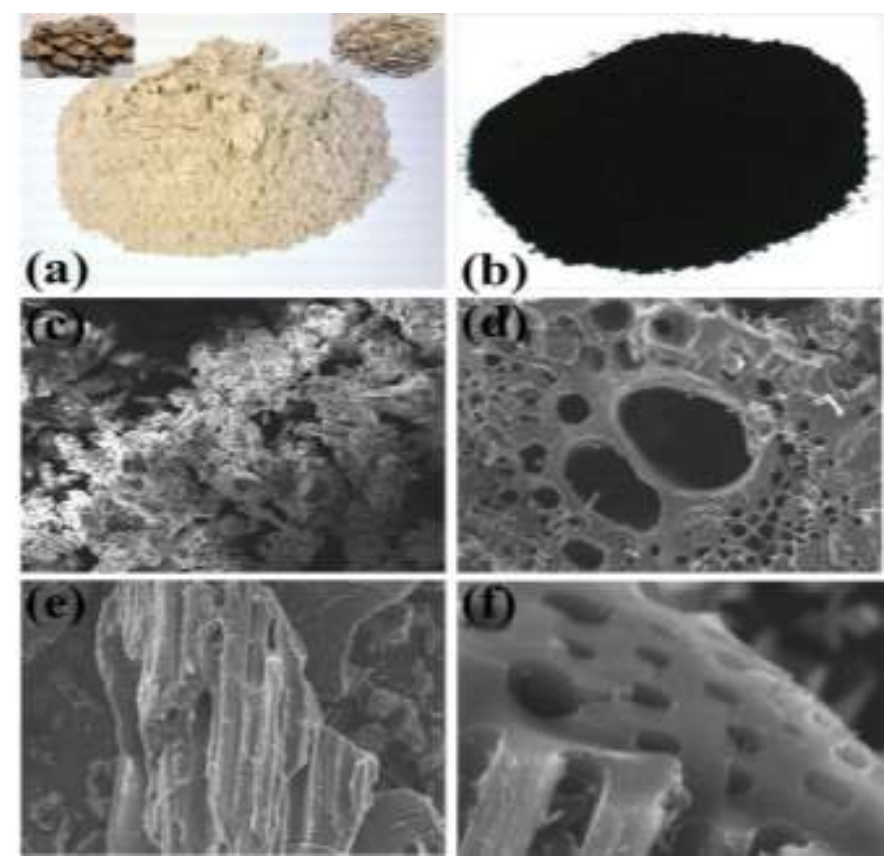

Figure 5. Digital Images (a) RDF, (b) AC and SEM of (c) RDFC (d) AC$\mathrm{H}_{3} \mathrm{PO}_{4}(e) \mathrm{AC}-\mathrm{KOH}(f) \mathrm{AC}-\mathrm{ZnCl}_{2}$

\section{Conclusion}

The ACs were prepared from RDF a biomass waste using different chemical activating agents like $\mathrm{H}_{3} \mathrm{PO}_{4}, \mathrm{KOH}$ and $\mathrm{ZnCl}_{2}$. The $60 \%$ for $\mathrm{AC}-\mathrm{H}_{3} \mathrm{PO}_{4}, \mathrm{AC}-\mathrm{ZnCl}_{2}$ and $40 \% \mathrm{AC}-\mathrm{KOH}$ concentration, $3 \mathrm{~h}$ carbonization time and $400^{\circ} \mathrm{C}$ carbonization temperature are the optimum conditions at which the highest BET surface areas were obtained. The High surface area ACs prepared from RDF at lower carbonization temperature and can be used as an adsorbent for purification of industrial wastewater and removal of gases and other hazardous compounds. Therefore, the use of RDF for the ACs preparation is significant from the perspective of economic and environmental aspects as they are available abundantly.

\section{v. Acknowledgment}

This Research was supported by King Saud University, Deanship of Scientific Research, College of Science Research Center.

\section{References}

[1] M. Smisek, S. Cerny, Active Carbon: Manufacture, Properties and Applications, Elsevier Publishing Company, New York, (1970).

[2] P. Sugumaran, V. Priya Susan, P. Ravichandran, S. Seshadri, Production and Characterization of Activated Carbon from Banana Empty Fruit Bunch and Delonix regia Fruit Pod, Journal of Sustainable Energy \& Environment., 3, 125 (2012).

[3] Z. Hu, M. P. Srinivasan, Preparation of high-surface-area activated carbons from coconut shell, Microporous and Mesoporous Materials., 27, 11 (1999). 
[4] A. Ahmad, H. M. Al-Swaidan, A. H. Al-ghamdi, Activated Carbon Preparation and Characterization from Date Fronds Biomass by Chemical Activation, Asian Journal of Chemistry., 26, 7833 (2014).

[5] I. I. Gurten, M. Ozmak, E. Yagmur and Z. Aktas, Biomass Bioenergy., 37, 73 (2012).

[6] W. Li, J. Peng, L. Zhang, K. Yang, H. Xia, S. Zhang, S.H. Guo, Preparation of activated carbon from coconut shell chars in pilot-scale microwave heating equipment at $60 \mathrm{~kW}$, Waste Management., 29, 756 (2009).

[7] I. A.W. Tan, A. L. Ahmad, B. H. Hameed, Optimization of preparation conditions for activated carbons from coconut husk using response surface methodology, Chemical Engineering Journal., 137, 462 (2008).

[8] A. Arami-Niyaa, W. M. A. W. Dauda, F. S. Mjalli, F. Abnisaa, M. S. Shafeeyan, Production of microporous palm shell based activated carbon for methane adsorption: Modeling and optimization using response surface methodology, Chemical engineering research and design., 90, 776 (2012).

[9] M. A. Nahil, P. T. Williams, Pore characteristics of activated carbons from the phosphoric acid chemical activation of cotton stalks, Biomass and Bio energy., 37, 142 (2012).

[10] K. Nuithitikul, S. Srikhun, S. Hirunpraditkoon, Influences of pyrolysis condition and acid treatment on properties of durian peel-based activated carbon, Bioresource Technology., 101, 426 (2010).

[11] A. Cheenmatchaya, S. Kungwankunakorn, Preparation of Activated Carbon Derived from Rice Husk by Simple Carbonization and Chemical Activation for Using as Gasoline Adsorbent, International Journal of Environmental Science and Development., 5, 171 (2014).

[12] K. Y. Foo, B. H. Hameed, Potential of jackfruit peel as precursor for activated carbon prepared by microwave induced $\mathrm{NaOH}$ activation, Bioresource Technology., 112, 143 (2012).

[13] S. Ucar, M. Erdem, T. Tay, S. Karagoz, Preparation and characterization of activated carbon produced from pomegranate seeds by $\mathrm{ZnCl}_{2}$ activation, Applied Surface Science., 255, 8890 (2009).

[14] A. N. A. El-Hendawy, S.E. Samra, B.S. Girgis, Adsorption characteristics of activated carbons obtained from corncobs, Colloids and Surfaces A., 180, 209 (2001).

[15] W. Tongpoothorn, M. Sriuttha, P. Homchan, S. Chanthai, C. Ruangviriyachai, Preparation of activated carbon derived from Jatropha curcas fruit shell by simple thermo-chemical activation and characterization of their physico-chemical properties, Chemical engineering research and design., 89, 335 (2011).

[16] T. Budinova, E. Ekinci, F. Yardim, A. Grimm, E. Björnbom, V. Minkova, M. Goranova, Characterization and application of activated carbon produced by $\mathrm{H}_{3} \mathrm{PO}_{4}$ and water vapor activation, Fuel Processing Technology., 87, 899 (2006).

[17] J. Gao, D. Kong, Y. Wang, J. Wu, S. Sun, P. Xu, Production of Mesoporous Activated Carbon from Tea Fruit Peel Residues and Its Evaluation of Methylene Blue Removal from Aqueous Solutions, BioResources., 8, 2145 (2013).

[18] I. Ozdemir, M. Şahin, R. Orhan, M. Erdem, Preparation and characterization of activated carbon from grape stalk by zinc chloride activation, Fuel Processing Technology., 125, 200 (2014).

[19] N. Ferrera-Lorenzo, E. Fuente, I. Suárez-Ruiz, B. Ruiz, KOH activated carbon from conventional and microwave heating system of a macroalgae waste from the Agar-Agar industry, Fuel Processing Technology., 121, 25 (2014).

[20] O. Gercel, A. Ozcan,A. S. Ozcan, H. F. Gercel, Preparation of activated carbon from a renewable bio-plant of Euphorbia Rigida by $\mathrm{H}_{2} \mathrm{SO}_{4}$ activation and its adsorption behavior in aqueous solutions, Applied surface science., 253, 4843 (2007).

[21] P. Alvarez, C. Blanco, M. Granda, The adsorption of chromium (VI) from industrial wastewater by acid and base-activated lignocellulosic residues, Journal of Hazardous Materials., 144, 400 (2007).

[22] Y. A. S. Alhamed, M. I. Abdulsalam, Activated Carbon from Palm Tree Branches, Proceedings of the Fourth Saudi Engineering Conference., 5 , 51 (1995).
[23] R. S. Al-Juruf, Biological degradation of date-palm fronds used in construction, Proceeding of the 6th Saudi Engineering Conference KFUPM., 3, 217 (2002).

[24] SAC. Test methods of wooden activated carbon (B73) determination of heavy metals GB/T 12496.22-1999. SAC. Haidian District Beijing (China): Chinese Academy of Forestry Forest Research Institute of Chemical Industry; 1999.

[25] Serrana VG, Villegas JP, Florindo AP, Valle CD, Calahorro CVJ, FTIR study of rockrose and of char and activated carbon. Journal of analytical and applied pyrolysis, 36, 71-80, (1996)

[26] A. Kumar, L. Wang, Y. A. Dzenis, D. D. Jones, M. A. Hana, Thermogravimetric characterization of corn stover as gasification and pyrolysis feedstock, Biomass Bioenergy., 32, 460 (2008).

[27] H. Yang, R. Yan, H. Chen, D. Ho Lee, C. Zheng, Characteristics of hemicellulose, cellulose and lignin pyrolysis, Fuel., 86, 1781 (2007).

[28] D. Kalderis, S. Bethanis, P. Paraskeva, E. Diamadopoulos, Production of activated carbon from bagasse and rice husk by a single-stage chemical activation method at low retention times, Bioresource Technology., 99, 6809 (2008).

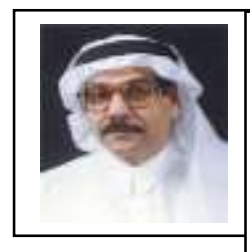

Prof. Hassan Mohammed Al-Swaidan is currently a Professor in King Saud University. He received Bachelor of Chemistry from King Saud University, Riyadh Saudi Arabia in 1976. He obtained his M.Sc. degree in Analytical Chemistry (1982) from University of Washington U.S.A. and subsequently his $\mathrm{PhD}$ in Industrial Analytical Chemistry (1983) from University of Washington U.S.A. His area of research: Industrial Analytical Chemistry, Environmental Chemistry, Activated Carbon Material.

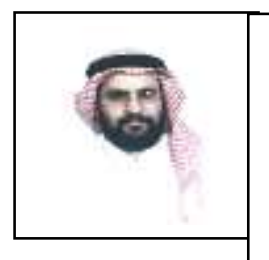

Prof. Ahmad Hamid Alghamdi received Bachelor of Chemistry from King Saud University, Riyadh Saudi Arabia in 1993. $\mathrm{He}$ received his M.Sc. in Analytical Chemistry and instrumentation (1997) from Loughborough University-UK and subsequently his $\mathrm{PhD}$ in Electro-analysis (2000) from Loughborough UniversityUK. His area of Specialization: Chemistry, Advance analytical chemistry (Electro-analysis, Spectroscopy). $\mathrm{He}$ is Professor in King Saud University.

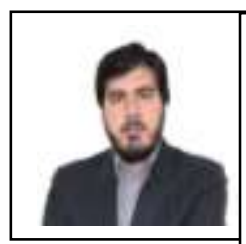

Ashfaq Ahmad is currently a $\mathrm{PhD}$ student (Analytical Chemistry) at King Saud University Riyadh Saudi Arabia. He received the M.Sc. degree from University of Malakand Pakistan. His research interest includes Activated Carbon Preparation from biomass and its adsorption application. 